\title{
BASE NACIONAL COMUM CURRICULAR NO OESTE DA BAHIA: políticas da tradução em relatos de professores
}

\author{
Clívio Pimentel Júnior \\ Universidade Federal do Oeste da Bahia - UFOB, Brasil
}

\begin{abstract}
Resumo
O texto focaliza a discussão sobre as políticas da tradução da Base Nacional Comum Curricular no Oeste da Bahia apresentadas em relatos de professores. Aborda a noção de tradução em diferentes registros teóricos pós-estruturais e pós-fundacionais, destacando a forma como tais operadores interpretativos permitem configurar as discussões em torno do trabalho com políticas de currículo, explorando suas contribuições e potencialidades para o campo. A partir do material empírico mobilizado, discute-se as implicações do processo de implementação da BNCC enquanto política do tipo padrão, problematizando seu anseio em alinhar, padronizar e estancar as disputas discursivas pela significação do currículo na relação com o outro nos mais distintos espaços e tempos educacionais. Defende-se o fracasso normativo de políticas erigidas sobre a tentativa de substituição e desprezo das culturas e trajetórias profissionais e experiências pedagógicas e curriculares dos sujeitos que engendram os cotidianos escolares.
\end{abstract}

Palavras-chave: Base Nacional Comum Curricular; Política de Currículo; Tradução.

\begin{abstract}
The text focuses on the discussion on the translation policies of the National Curriculum Common Core in Western Bahia presented in teaching reports. It addresses the notion of translation in different post-structural and post-foundational theoretical registers, highlighting the way in which such interpretative operators allow configuring discussions around work with curriculum policies, exploring their contributions and potential for the field. Based on the empirical material mobilized, the implications of the BNCC implementation process as a standard policy are discussed, questioning its desire to align, standardize and stop discursive disputes for the meaning of the curriculum in relation to the other in the most different educational spaces and times. It defends the normative failure of policies built on the attempt to substitute and disregard professional trajectories and cultures, and pedagogical and curricular experiences of the subjects who engender school daily life.
\end{abstract}

Keywords: National Curriculum Common Core; Curriculum Policy; Translation. 


\section{Introdução}

O processo que se convencionou chamar implantação / implementação da Base Nacional Comum Curricular (BNCC) nos estados e municípios brasileiros vem ocorrendo em múltiplos espaços e tempos educacionais, a partir da implementação de uma série de materiais produzidos em articulação política entre o Ministério da Educação (MEC), as secretarias de educação e, em alguns municípios, entidades do terceiro setor (MACEDO, 2019). O processo é marcado por uma inundação do chão da escola com orientações políticas diversas disseminadas por meio de materiais didáticos, atores partícipes das implementações, professores, coordenadores e articuladores de área, entre outros sujeitos escolares, sinalizando para uma intensa disputa política pela significação e tradução da BNCC. Uma disputa que vem se mostrando, em certa medida, esvaziada do debate em torno da própria necessidade de um padrão ${ }^{1}$ curricular nacional e de como os professores lidam com políticas nas escolas, e mais interessada em dizer-lhes como o currículo e o ensino devem ser para atingir determinadas finalidades identitárias de formação. As escolas hoje encontram-se interpeladas por sujeitos e políticas que, de modo mais ou menos efetivo nesse intento, pretendem, conforme orientações do próprio documento da BNCC, alinhar os sentidos da docência, do currículo, da didática e da aula às soluções padronizadas para o ensino. Embora seja um processo sempre presente, com maior ou menor intensidade política em suas configurações históricas, essas interpelações e enquadramentos discursivos por meio dos quais as escolas vêm sendo produzidas como espaços necessitados de padronização curricular, apresentam características singulares no que tange ao trabalho centralizador com políticas nos espaços educativos. Muitos estudos vêm nos provocando a pensar na implementação da BNCC no Brasil como parte de um fluxo global de políticas curriculares, possibilitando pensar que alinhamento, padronização, entre outras metáforas de controle e homogeneização, são processos constitutivos de políticas do tipo padrão gerenciadas por agentes públicos e privados articulados em torno da centralização curricular (BALL, 2014; BALL; MAGUIRE; BRAUN, 2016; ANDERSON-LEVITT, 2017; HYPOLITO, 2019, FRANGELLA, 2019).

Concordando com Ball (2001; 2014), Anderson-Levitt (2017) e Hypolito (2019), acredito que é importante desenvolver uma compreensão ampliada sobre os efeitos dessas agendas e formas políticas da padronização curricular a nível (inter)nacional, inserindo a discussão da BNCC no cenário global mais amplo, no qual a influência e participação dos agentes e organismos econômicos multilaterais vêm hegemonizando sentidos para a formação e o currículo. Tanto Ball (2014) como Anderson-Levitt (2017), por exemplo, discorrem sobre os fluxos globais de conceitos e perspectivas pedagógicas para o currículo e a avaliação que se atualizam nas mais diversas políticas (inter)nacionais de padrão curricular. Fluxos que envolvem uma específica forma de significação do fazer da política nas escolas, apresentando-a como numa espécie de linha de montagem que conecta, de modo determinístico, docência, currículo, didática, aula, ensino, aprendizagem, com a mensuração precisa dessa última por avaliações em larga escala. As avaliações nessas políticas cumprem o papel de verificação padronizada de eficiência do ensino pelas aprendizagens, ou seja, estão 
comprometidas com a accountability. Ball, Maguire e Braun (2016) nomeiam esse processo da política como deliverology, uma ciência da entrega, fazendo referência à produção discursiva da educação como uma intervenção na formação do sujeito capaz de realizar uma entrega encomendada, baseada em testagens e métricas passíveis de serem precisamente ajustadas e calculadas. Dessa forma, essas coalizões globais descentradas de governança das políticas educacionais e de currículo, atuantes, agora, com maior intensidade nessa fase de implementação, representadas por articulações entre secretarias municipais, estaduais e agentes privados ${ }^{2}$, acabam por materializar políticas de linguagem baseadas em evidências e soluções para as escolas e os agentes envolvidos no fazer da política. Essas articulações e produções discursivas, por sua vez, fazem emergir políticas de linguagem comprometidas com a fundação da educação como um empreendimento do cálculo (BIESTA, 2013; 2016). Uma política de linguagem que hegemoniza e põe em circulação um imaginário objetificado dos sujeitos, do currículo e da educação, catalisando, a partir das identificações que consegue pactuar, sentidos restritivos, quiçá inviabilizantes, para pensar a escolarização e a educação como prática da diferença; isto é, como prática que suscita o (im)possível acontecimento da singularidade (DERRIDA, 2004; PIMENTEL-JÚNIOR; CARVALHO; SÁ, 2018).

Neste texto, tendo em vista esses contornos e fluxos globais de governança neoliberal de política-padrão para os currículos, e seus desdobramentos e articulações políticas locais em torno de sua implementação, volto-me, em um nível escalar mais contextual, à discussão sobre as políticas de tradução da BNCC no Oeste da Bahia, mais especificamente, na cidade de Barreiras, a partir de relatos de professores e professoras. Esse foco contextual mais específico justifica-se tendo em vista a constitutividade e singularidade na atuação das políticas nos contextos (BALL; MAGUIRE, BRAUN, 2016), e as possíveis nuances mais específicas e singulares que a fase implementação da BNCC vem fazendo emergir nos distintos espaços e tempos educacionais. Acredito que às investigações sobre as formas de sociabilidade e redes de governança global das políticas curriculares, pode ser importante somarem-se esforços investigativos que busquem entender as traduções e atuação das políticas em níveis mais locais; um enfoque que, possivelmente, permitirá amplificar a defesa em torno da ideia de que políticas alçadas à universalidade por uma decis $\tilde{a}^{3}$ pela centralidade, desprovidas de espaço para negociações com as singularidades culturais, levadas à cabo pelo desprezo das experiências dos sujeitos para os quais elas são endereçadas, fracassam em sua ânsia normativa (BALL; MAGUIRE; BRAUN, 2016; BUTLER, 2017; PIMENTEL-JÚNIOR, 2020). Para tanto, opero uma descrição interpretativa das políticas tradutórias dos professores manifestadas em depoimentos sobre o momento político da fase de implementação nesse contexto particular.

Ao perseguir este objetivo, estruturei a argumentação do texto da seguinte forma: (i) primeiro, apresento uma discussão teórico-metodológica sobre a noção de tradução nos estudos de Ball, Maguire e Braun (2016), cotejando-a com os estudos da tradução em registro desconstrucionista (DERRIDA, 1991; 2001; 2016), aliados por sua vez, aos estudos de currículo (LOPES; MACEDO, 2011) e política (LACLAU; MOUFFE, 2015) em chave pósestrutural que também informam este trabalho ${ }^{4}$. Por esse caminho, busco fazer um cotejamento não oposicional entre as perspectivas de tradução apresentadas, tentando 
explorar as nuances interpretativas que esses operadores permitem conceber na análise de políticas curriculares; (ii) em seguida, apresento uma seção na qual os relatos de professores sobre o processo de tradução da BNCC no Oeste da Bahia são discutidos. Focalizo as políticas tradutórias apresentadas pelos professores entendendo-as como práticas diferenciais e políticas radicalmente contextuais de sentido com as quais qualquer norma curricular precisa negociar para vir a ser realizada nas escolas, sob pena de fracasso - embora, acredito, toda norma já esteja, por si só, habilitada pelo seu próprio fracasso (BUTLER, 2017); (iii) por fim, concluo ponderando sobre a irrefreável e complexa disputa de sentidos que se dá entre as forças homogeneizantes da política padrão como a BNCC, e as traduções que estão a ocorrer nos múltiplos espaços e tempos escolares, fazendo-nos interrogar diversos aspectos desse tipo de política (que envolvem desde a decisão por esse tipo de política, até seus aspectos pedagógicos específicos) para pensar a educação e o currículo escolar. Com isso, espero conseguir apresentar características da implementação da BNCC no contexto investigado destacando possíveis singularidades e, ao mesmo tempo, realçando aspectos que as conectam à dinâmica e agenda global de funcionamento de políticas do tipo padrão.

\section{Tradução nas Políticas Educacionais e de Currículo}

Neste momento, busco explorar a noção de tradução nos registros teóricos que venho utilizando nas pesquisas em políticas de currículo, realçando as nuances interpretativas, as possíveis aproximações e distanciamentos, e o modo como (re)configuram leituras do trabalho com políticas nas escolas. Ball, Maguire e Braun (2016, p. 12-14) apresentam uma teoria extensa de atuação das políticas, buscando mostrar "como as políticas tornam-se vivas e atuantes (ou não) nas escolas, [...] traçando como as forças econômicas e sociais, as instituições e as pessoas, os interesses, os eventos e as oportunidades interagem" nesse processo. Para eles, a atuação das políticas envolve processos criativos de interpretação e recontextualização, "ou seja, a tradução de textos em ação e as abstrações de ideias políticas em práticas contextualizadas" (BALL; MAGUIRE; BRAUN, 2016, p. 14). Segundo os autores, esse processo envolve sempre "interpretação de interpretação, embora o grau do jogo ou a liberdade de interpretação varie de política para política em relação aos aparatos de poder em que estão estabelecidos e dentro dos limites e das possibilidades do contexto" (BALL; MAGUIRE; BRAUN, 2016, p. 14).

Desta forma, os autores buscam realçar diversos aspectos da atuação das políticas nas escolas, dentre eles, destaco: (I) políticas são tecnologias de ordenamento sempre tramadas em múltiplas escalas e a partir de múltiplos discursos, e envolvem forças políticas que estão para além dos muros da escola; (II) políticas são sempre colocadas em ação em contextos específicos com materialidades, culturas e capacidades de resposta variadas; (III) relações de poder buscam domesticar a produção de sentidos atribuídos às políticas nos contextos, tentando disciplinar aquilo que é interpretado pelos atores sociais; (IV) apesar do grau condicionado de liberdade interpretativa, políticas são colocadas em ação tendo em vista a construção de sentido pelos sujeitos, isto é, a agência dos atores políticos para os quais elas 
são endereçadas, os esquemas de fazer sentido da política; (V) o contexto onde políticas são atuadas é mais do que um pano de fundo sobre o qual sujeitos buscam interpretar e traduzir orientações normativas; trata-se de uma força ativa viabilizando e restringindo sua realização; (VI) se o contexto é força ativa na política, escolas não podem ser concebidas como espaços homogêneos e indiferenciados, tampouco os sujeitos que engendram seu cotidiano; (VII) por fim, "a política também é sempre apenas parte do que os professores fazem. Há mais sobre o ensino e a vida escolar do que a política" (BALL; MAGUIRE; BRAUN, 2016, p. 18).

Todos os aspectos citados fazem os autores avançar em uma teoria da atuação - e não implementação - da política, definindo-a como um processo "dinâmico e não-linear de todo o complexo que compõe o processo da política, do qual a política na escola é apenas uma parte" (BALL; MAGUIRE; BRAUN, 2016, p. 18), e envolve tradução, interpretação e reconstrução em diferentes espaços e tempos educacionais, cujos recursos materiais, locais e humanos utilizados fazem emergir um processo complexo e híbrido de realização. Não pretendo ser exaustivo na apresentação da teoria da atuação dos autores neste texto. Meu foco vai recair sobre a compreensão de contexto, interpretação e tradução apresentados por eles. Cito esses aspectos apenas para destacar que a teoria da atuação permite, desde já, problematizar qualquer linguagem baseada em concepções lineares, de cima para baixo, de alinhamento e homogeneização, no trabalho com políticas nas escolas, mostrando que esse é um processo bem mais complexo e disputado do que a ideia simplificadora de implementação direta presente na linguagem administrativa de política, dentre elas, a de política padrão.

Nos estudos de Ball, Maguire e Braun a noção de contexto ganha contornos complexos. É possível conceber que, para eles, o contexto é uma produção simultaneamente discursiva, simbólica, geohistórica e material, na medida em que assumem como pressuposto que "a política cria o contexto, mas o contexto também precede a política" (BALL; MAGUIRE; BRAUN, 2016, p. 36). De acordo com eles, políticas são colocadas em ação em espaços com condições materiais, culturas profissionais, recursos infraestruturais variados e histórias singulares. Os autores argumentam que políticas podem ser colocadas em ação de diferentes formas e com diferentes intensidades, dentro dos contextos institucionais escolares, na medida em que as múltiplas dimensões dos fatores elencados para o contexto condicionam a maneira como a política toma forma. Outro aspecto importante a destacar na teorização dos autores diz respeito à ideia de que levar o contexto a sério na análise de atuação da política significa perceber que as culturas profissionais, os contextos materiais, os contextos internos e externos às instituições, precisam ser levados em conta, para além da ideia de que são meras superfícies neutras sobre as quais uma dada política acontece.

Ball e colaboradores realçam que levar o contexto a sério significa entender que fatores como disponibilidade de recursos, capacidade de recrutar e reter professores, capacidade dos estudantes em responder a um determinado perfil formativo previsto em projeto pedagógico, capacidade da localidade em ser atrativo profissional, capacidade orçamentária, entre outros, fazem das escolas locais únicos de atuação de políticas (BALL, 1994; BALL; MAGUIRE; BRAUN, 2016). Defendendo que o trabalho com políticas envolve a mobilização de uma caixa de ferramentas ${ }^{5}$ com recursos variados para tentar dar conta de fazer emergir a complexidade envolvida nesse processo, os autores conectam e combinam a noção de 
contexto, enquanto recurso heurístico, às noções de interpretação e tradução. Trata-se de uma aposta dos autores em fazer as investigações de políticas tornarem-se mais nuançadas e diversificadas em termos de teorização e compreensão dos dados obtidos.

Para Ball e colaboradores, a interpretação da política pode ser entendida como uma leitura inicial que busca a construção de sentido do texto da política. Trata-se, segundo eles, de uma decodificação ao mesmo tempo retrospectiva e prospectiva, na medida em que leva sempre em conta a cultura e a história da instituição, bem como as biografias dos atoreschave e as materialidades do contexto. Assim, segundo os autores, as interpretações são sempre situadas, colocadas em ação num jogo de contraposições em relação a outros aspectos que estão em jogo na política, e levando em conta também os interesses institucionais e dos sujeitos, bem como as consequências que poderiam resultar da ação com a política. Trazendo a noção de tradução à cena, a interpretação, segundo eles, pode ser entendida como "um compromisso com a linguagem da política, ao passo que a tradução está mais próxima às linguagens da prática" (BALL; MAGUIRE; BRAUN, 2016, p. 69). Os autores fazem uma distinção heurística entre tradução e interpretação para explicar como políticas são atuadas. Nessa direção, enquanto a interpretação é o momento de explicação, esclarecimento e entendimento mais global da política, a tradução seria o gesto prático que emerge a partir desse entendimento, "uma espécie de terceiro espaço entre políticas e práticas. É um processo iterativo de fazer textos institucionais e colocar esses textos em ação, literalmente atuar sobre a política" (BALL; MAGUIRE; BRAUN, 2016, p. 69).

A tradução nesse registro está mais ligada ao fazer atuar da política nas escolas. Para os autores, esse momento da atuação das políticas guarda estreita relação com a transformação da política em prática, materiais, ações e procedimentos, é uma recodificação da política em atividade, em ação. Uma recodificação prática sempre mediada em relação aos contextos específicos, às culturas de destinatários e de sujeitos, e às lógicas da prática da sala de aula. Nesse sentido, "a tradução acontece em relação aos imperativos e às exortações com diferentes tipos de criatividade e espaços de invenção e produção em cada caso" (BALL; MAGUIRE; BRAUN, 2016, p. 70), ou seja, a diversidade de espaços e tempos institucionais, sujeitos e seus interesses, locais de atuação e envolvimento em redes de identidade dentro das instituições, implicam no processo de "interação direta entre a política e a prática" (BALL; MAGUIRE; BRAUN, 2016, p. 70).

Além das dimensões contextuais mais amplas, os autores defendem que as traduções das políticas nas escolas também se envolvem com outros tipos de prioridades de sala de aula e valores, e competem pela atenção com outras políticas em curso. Esse envolvimento acaba por agir desfazendo princípios rígidos da política na escola e na sala de aula, envolvendo negociação constante com sujeitos e processos em curso no cotidiano das escolas. Para eles, tendo em vista esse cenário complexo das políticas nas escolas, seria mais producente falar em infiltração da política nas escolas, em gotejamento, em escorrimento para dentro dos ambientes institucionais, tornando-se parte de uma bricolagem mais ampla que estrutura as atividades de ensino e aprendizagem. Trata-se de metáforas que permitem complexificar o movimento de acolhimento de orientações normativas e permitem desfazer a ideia de uma realização fixa e diretiva da identidade da política na escola e na sala de aula. Além desses 
aspectos, afirmam os autores que "nós não deveríamos assumir que a política é a única influência sobre o comportamento dos professores" (BALL; MAGUIRE; BRAUN, 2016, p. 72), possibilitando pensar que a sala de aula vai muito além dos anseios político-normativos. Assim, com base nesses conceitos-chave da teoria de Ball, Maguire e Braun, é possível afirmar que a ideia de contexto, para eles, permite realçar a distinção entre interpretação e tradução, operando no sentido de fazer esta última dialogar com as variáveis de modo mais encarnado em um dado momento de transformação da política em ação. Ou seja, trata-se de um encadeamento de conceitos e recursos heurísticos que buscam dar conta de fazer a conexão entre os espaços e tempos de atuação da política, suas dimensões simbólicas, materiais e discursivas, o processo de fazer sentido da política, e, finalmente, a conversão da política em ação. Cada um desses níveis de trabalho com políticas são habitados por inúmeros fatores e aspectos contextuais, biográficos, geohistóricos e materiais, de modo a complexificar a compreensão do fenômeno da atuação da política nas escolas.

Embora as teorizações de Ball e colaboradores representem um avanço inquestionável nos estudos de políticas educacionais e de currículo nas escolas, na medida em que permite complexificar o entendimento das maneiras pelas quais essas tecnologias do poder acontecem nesses espaços, pondo em xeque, sobretudo, modos verticalizados e administrativos de conceber a política educacional na perspectiva da conformidade e da reprodução, a noção de contexto dos autores, bem como a distinção entre tradução e interpretação, permanecem, ainda, mantendo uma solidez sociológica dos contextos e da própria produção cultural de sentido difícil de sustentar em aprofundamento no registro pós-estrutural. Embora acredite que a teoria da atuação complexifica o fenômeno da política na escola, acredito que criar unidades sociológicas e camadas de recursos heurísticos entre interpretação e tradução, relegando a esta última o espaço da transformação do sentido na prática (leitura ativa, nas palavras dos autores), não permite, ainda, compreender a própria tradução como processo de criação de sentido na leitura e na ação, de ordem babelizante, desconstruindo a ideia de uma origem do sentido a ser convertida em ação e de uma separação entre entendimento e ação. Concordando com Lopes, Cunha e Costa (2013), defendo que há, ainda, rastros de uma ideia de trajetória, de algo a ser transportado de um lugar a outro, na teorização da atuação da política, embora complexificada e nuançada em muitos aspectos, permitindo desfazer a linearidade nesse trajeto.

Desta forma, defendo que a tradução no registro de Ball encontra-se, ainda, cerceando a diferença entre recursos heurísticos de fazer o sentido virar ação. Embora em sua abordagem a tradução esteja presente nesse processo de fazer o sentido da política virar ação prática, reconhecendo as deformidades constitutivas dessa conversão, acredito que essa é uma previsão heurística trabalhada na teoria de modo a prever as múltiplas formas de emergir da diferença. Minha questão é que a previsão da deformidade imposta pela tradução aqui é algo, a meu ver, que, em si, empobrece o horizonte da tradução enquanto emergência, no sentido dado nas ciências naturais, da ordem imprevisível de algo que irrompe de interações complexas. A meu ver, o encadeamento da tradução e a sua conexão explícita à ideia de uma leitura ativa da política, à transformação prática, uma tecnologia da ação, acaba por condenar, em alguma medida, a diferença ao espaço previsível da conversão e ao pragmatismo da ação. 


\section{Tradução no registro desconstrucionista}

A tradução enquanto prática da diferença, como venho entendendo no registro derridiano, permite questionar tanto essa imbricação tecnológica da tradução em uma cadeia previsível de efeitos da política ligada a algo prático, como o oposicionismo entre, de um lado, a origem/essência do sentido na política, e, de outro, a aparência/representação tradutória enquanto algo complementar do sentido original. Além disso, ela aponta que a tradução pode não ser só a conversão previsível do sentido em ação. A tradução, possivelmente, está lá antes mesmo da ação. Quando a diferença é considerada constitutiva, como na compreensão derridiana, a tradução e o sentido emergentes são não só imprevistos, irruptivos, como também (re)criações do sentido suposto como original (DERRIDA, 2001; WOLFREYS, 2009; SISCAR, 2012). Deslocar a tradução no registro desconstrucionista para pensar a atuação das políticas curriculares nas escolas apresenta algumas implicações que permitem nuançar e complexificar ainda mais a leitura desses fenômenos escolares. Assumir a tradução enquanto prática da diferença pode ressignificar e ampliar o entendimento do que seja "colocar textos em ação" (BALL; MAGUIRE; BRAUN, 2016, p. 69).

Assim o primeiro aspecto que destaco no registro desconstrucionista é a mudança na noção de contexto. A noção derridiana de contexto compreende esse construto como uma unidade interpretativa tramada na impossibilidade de exaurir de uma vez por todas os sentidos daquela unidade sociológica construída em nome do contexto (DERRIDA, 1991). Ou seja, há uma abertura, um elogio à infinitude, na construção contextual derridiana, na medida em que a indecidibilidade presente nas operações textuais habitam o falar em nome do contexto, colocando sua significação, mesmo que atenta às materialidades e concretudes, sempre em disputa, incluindo aí o processo de seleção daquilo que se elege para delinear um contexto.

No registro da teoria da atuação, a discussão de contexto, embora realce seus aspectos discursivos, aborda também seus aspectos mais fortemente ligados à contextos materiais, profissionais, de inserção e externos relativos à um dado espaço-tempo institucional. A noção derridiana, por sua vez, levando essas questões em conta, realça a textualidade do contexto, sua construção discursiva. Preocupa-se mais, a meu ver, com a definição do contexto, a operação discursiva em todos os seus aspectos que fizeram emergir uma da significação de contexto, e aquilo que ela precisou excluir para constituir-se. Nesse sentido, a noção de contexto derridiana, a meu ver, aprofunda o entendimento desse construto como uma produção discursiva e, assim, amplifica a própria disputa narrativa pela representação do contexto, seus limites, inclusões e exclusões constitutivas, chamando atenção para aquilo que é elencado e deixado de fora para o fechamento de uma unidade sociológica como o contexto. É justamente a clausura, o fechamento, o definir, do contexto que a noção derridiana permite complexificar, pluralizando seus sentidos e disseminando aquilo que parece estar, suposta e inexoravelmente, dado em uma unidade contextual, permeabilizando bordas e fronteiras (BENNINGTON; DERRIDA, 1996; DERRIDA, 2001). Como Wolfreys (2009) nos diz, em Derrida, nenhum contexto é finito, nenhum contexto exclui outros como textos, e por mais 
que tendamos a conectar ideias e noções a contextos particulares, elas nunca permanecerão fixamente no lugar, naquele contexto. As ideias e noções estarão sempre a se deslocar da fixidez, transportando-se para outros contextos, produzindo novas identificações e transformando seus significados. A operação que visa definir um contexto é, portanto, uma operação sempre remetida ao fracasso e à precariedade da circunscrição de um espaço plenamente suturado em termos de representação de um contexto. Além da noção de contexto, a noção derridiana de tradução apresenta nuances que envolvem a indecidibilidade em muitos aspectos, ampliando seu escopo de ação para além da ação.

A tradução no registro desconstrucionista pode ser - e não deve ser - entendida como aquela tarefa intersticial envolvida entre a necessidade e a impossibilidade de tudo quererdizer sobre um dado texto, isto é, habitada pela (im)possibilidade constitutiva de carregar um dado sentido e dar conta de compreender um sentido completo do texto em tradução (BENNINGTON; DERRIDA, 1996; WOLFREYS, 2009; SISCAR, 2012). A tradução, nesse sentido, produz uma textualidade outra, um tecido textual ao mesmo tempo singular e desapossado de plena autenticidade. No registro derridiano, a tarefa da tradução impõe um endividamento inevitável ao tradutor em relação à fonte original ao qual remete-se na busca do sentido. Nesse sentido, o movimento textual colocado em operação na tradução é da ordem do inacabamento constante, sem um sentido absoluto de início e de origem do qual parte uma transformação do sentido. A tradução consuma outra textualidade, outra produção de sentido, também ela, criativa. A tradução produz "um texto que é, ao mesmo tempo, muito semelhante e completamente outro" (DERRIDA, 2001, p. 10) nos rastros daquelas fontes referenciais submetidas à operação da tradução.

Nessa direção, a tradução deixa de ser uma atividade complementar em relação à origem do sentido posto em um dado texto, isto é, deixa de ser compreendido como simulacro do sentido original, passando a ser uma criação endividada - o que impede de dizer qualquer coisa sobre qualquer texto - e, ao mesmo tempo, sempre outra em relação a esse mesmo texto (DERRIDA, 2001). Tanto porque uma tradução jamais exaure o sentido absoluto de um texto, como porque o texto, em si, a ser traduzido, é, também ele, desprovido de um próprio, ou seja, de um sentido único, absoluto. A fonte encontra-se, também ela, cindida, contaminada, marcada por aquilo que excede, primeira e primariamente, qualquer sentido em uma despossessão relacional (BUTLER, 2017). Desta forma, há uma intertextualidade que precede e excede tanto o texto original, se é que é possível usar essa palavra, como a tradução. Talvez, seja justamente no reconhecimento da falibilidade de qualquer operação tradutória no sentido de resgatar e transportar o sentido de um texto, desse endividamento devido ao outro, numa relação ética infinita, que Derrida assume a tradução como uma missão cujo engajamento, o dever, a dívida e a responsabilidade são imperativos. Entendo, assim, que o ser-tradução da tradução seria, portanto, a própria dívida envolvida na impossibilidade de tudo querer-dizer sobre um texto e um específico sentido, por eles se instituírem na singularidade. É possível conceber que o modo de ser da tradução comporta, nesse sentido, uma cena interlocutória devida ao outro inextirpável, cuja relação implica o envolvimento no estado da dívida do qual o tradutor jamais pode se livrar. A tradução seria (não mais que) a própria relação endividada com qualquer texto, o débito que emerge na abertura ao acaso do 
encontro com outros, a destinerrância à qual todo texto encontra-se, interminavelmente, submetida.

A operação da tradução, seguindo e desdobrando esse entendimento, envolve um tentar dizer incessante sobre algo no qual o tradutor se debruça. É uma operação deflagrada "no jogo da différance que faz com que nenhuma palavra, nenhum conceito, nenhum enunciado primordial venha a sintetizar e comandar, a partir da presença teleológica de um centro, o movimento e o espaçamento textual das diferenças" (DERRIDA, 2001, p. 21) envolvidas na tradução. Em outras palavras e em um esforço de síntese, essas questões nos permitem afirmar que a operação textual da tradução jamais começa desde uma origem absoluta, como também jamais é a pura repetição de uma mesmidade de sentido, ela jamais "se deixa prender na clausura de-limitada [e] pode assim continuar, indefinidamente" (DERRIDA, 2001, p. 20).

Com isso, penso que Derrida busca, dentre outras coisas jamais captáveis em minhas leituras, retirar a tradução da tecnologia da caixa logocêntrica (DERRIDA, 2001), isto é, da representação esquemática de uma tradução que tudo precisa captar e conter em relação ao sentido original daquilo que busca traduzir. A partir dele, seria impossível conceber uma noção esquemática e contenível da tradução não só porque o ser-original da origem é um modo de ser desapossado de pureza, aliás, um modo de ser cuja experiência é estruturada por uma rede de traços e vestígios (DERRIDA, 2001; 2004), como, também, porque o modo de ser da tradução emerge na cena e na relação ética infinita com a alteridade, fazendo da experiência um retorno sempre diferido às redes de traços e vestígios a partir das quais a tradução toma forma em sua (re)produção.

A partir dessas considerações, as implicações para pensar o acontecimento das políticas de currículo nas escolas são múltiplos. Se no registro das teorizações de Ball e colaboradores, a tradução já comporta algo de idiossincrático em sua conversão prática, em Derrida, (I) a tradução pode ser entendida como a própria possibilidade mesma de produzir algum sentido da política na escola. Ou seja, a tradução já é, em si, a própria interpretação precária e contingente da política. Compreender o fenômeno da política de currículo desde a noção de tradução (II) permite-nos desfazer qualquer aspecto de linearidade e/ou trajetória da política na escola. Trata-se do desfazimento da ideia mesma de percurso, de um endereçamento, que a política tenta produzir sobre as práticas e fazeres curriculares nas escolas, visando certas finalidades educacionais, também elas, previsíveis. Outro aspecto importante a destacar é a própria forma como a tradução lida com o contexto. Enquanto no registro de Ball e colaboradores o contexto delimita, em alguma medida, a tradução (o que pode ter algum nível de compatibilidade com Derrida), no registro da desconstrução derridiana (III) o contexto jamais consegue definir o sentido da tradução, apesar de todas as materialidades e temporalidades envolvidas. Se no registro de Ball as escolas jamais podem ser consideradas como espaços homogêneos de atuação de políticas, (IV) essa compreensão aprofunda-se e ganha nuances ainda mais complexas no registro derridiano, na medida em que o processo de recepção, interpretação e de tradução de política nas escolas é sempre muito mais do que uma recepção, é uma constante (re)criação indisciplinada de sentidos deflagrada no terreno da diferença. Assim, não há uma representação esquemática de trajetória da política em 
diferentes contextos nesse processo, mas uma composição outra de produção de sentidos. Por fim, a meu ver, (V) a tradução nesse registro está para além de uma leitura ativa da política se entendermos, por esse termo destacado, a conversão do sentido em ação. No registro derridiano, é possível conceber que a tradução diferencia, ela é o próprio movimento que distingue, que distancia, que faz algo outro nos escombros daquilo que foi submetido à tradução. Assim, ela está não só relacionada sempre a qualquer ação, como também está no próprio movimento interpretativo de leitura de qualquer texto, como uma política de currículo como a BNCC.

Portanto, partindo dos aspectos teóricos até aqui trabalhados, busco aprofundar, na próxima seção, a leitura que venho fazendo do processo de implementação da BNCC no Oeste da Bahia tomando como base alguns relatos de professores ${ }^{6}$. Relatos estes, entendidos como políticas da tradução que emergem nos discursos produzidos nas escolas, e que nos permitem afirmar algumas características da tradução da BNCC no contexto investigado.

\section{Políticas da Tradução da BNCC em relatos de professoras e professores}

O que venho nomeando como políticas da tradução da BNCC, a partir dos referenciais trabalhados, diz respeito às práticas da diferença colocadas em curso nos espaços e tempos educacionais pelos professores, em leituras e interpretações dos textos do documento da Base. De acordo com Ottoni (2005, p. 19) "a prática da diferença só se efetiva na tradução se pensarmos não só na multiplicidade das línguas, mas também no que essa multiplicidade encena: a tradução recíproca na produção e transformação infinita de significados”. Nessa direção, cotejando as perspectivas teóricas assumidas, busco pensar nas práticas da diferença como políticas de sentido criadas na relação interpretativa que se estabelece entre os professores e a política, tendo em vista o modo como as necessidades e negociações que emergem na tensão entre a norma e os contextos de práticas curriculares transformam significados da própria BNCC. Embora se trate de uma política curricular voltada à normatização de práticas, perseguir o entendimento das políticas da tradução não é um exercício voltado exclusivamente à compreensão das transformações dos sentidos atribuídos à política em situações de sala de aula. Isto é, busquei perseguir a forma como as normas são traduzidas em práticas sem focalizar restritamente a tradução na aula, mas na relação ampliada com a política ${ }^{7}$. Acredito que este específico enquadramento interpretativo permite desviar o foco dos sujeitos para as políticas tradutórias, evitando essencializações em torno de sujeitos escolares. Ou seja, passa a interessar as características das relações entre a BNCC e os praticantes curriculares, sem um olhar essencialista no sujeito enquanto um suposto portador do sentido único da tradução (PIMENTEL-JÚNIOR, 2020b).

De modo amplo, o processo de implementação da BNCC no Oeste da Bahia vem se caracterizando, de modo mais ou menos captável em meus esforços de interpretação ${ }^{8}$, por uma diversidade de posicionamentos dos sujeitos envolvidos no processo, contemplando diversos aspectos comuns aos desafios do trabalho com política padrão. Dentre essas características, podemos identificar: (I) a retórica discursiva da necessidade do padrão 
curricular como forma de garantir a qualidade e a igualdade de oferta de conhecimentos; (II) o desafio colocado na gestão do desempenho da implementação da BNCC, envolvendo diversos atores e o modo como produzem sentidos específicos para a política curricular, visando conformar os entendimentos entre os professores; (III) o inevitável cascateamento de-cima-para-baixo da política e a irradiação de padrões, materiais de apoio, orientações gerais, intérpretes, e outras tecnologias para a implementação; (IV) os discursos do esforço pessoal para o entendimento da BNCC, da necessidade de abertura à inovação curricular e metodológica pelos professores, do foco na implementação, e a consequente pressão gerada para os resultados do processo de padronização do currículo nas aprendizagens dos estudantes. Nesse sentido, de modo similar a outros contextos, a implementação da política padrão da BNCC no Oeste da Bahia "trabalha para articular uma versão específica e uma visão do que a escolaridade é e deveria ser, [...] que funciona por meio do estabelecimento de fortes vínculos entre o micromundo de interações da sala de aula e os objetivos de nível macro de padrões e realizações" (BALL; MAGUIRE; BRAUN, 2016, p. 108-109). Tais características discursivas captam e produzem identificações em diversas direções no contexto investigado, espacializando posicionamentos diversos.

Dentre esses posicionamentos, aqueles a favor da Base são comuns no contexto investigado e, comumente, trazem a demanda por mais formação e por mais materiais didáticos que auxiliem o trabalho de planejamento e de realização de atividades com a Base. Essas demandas, por si só, já permitem problematizar, desde já, a ideia de que a base e os princípios formativos propostos "não devem ser tomados como modelo obrigatório para o desenho dos currículos" (BRASIL, 2018, p. 31), pois, na medida em que gera anseios nos professores por materiais sobre como implementar explicitamente a política para produzir claramente os efeitos desejados, ela regula e normatiza fortemente o currículo. Ou seja, embora tente-se, a todo tempo e de modo reducionista, distinguir a BNCC do currículo ${ }^{9}$, a regulação sobre os efeitos de aprendizagem, sobre os planejamentos e sobre os operadores conceituais por meio dos quais a base se estrutura enquanto política evidencia, sim, que se trata de currículo. E trata-se de currículo não só pelos efeitos de regulação que gera sobre os professores, mas pela própria forma como busca criar percursos formativos, definir experiências de aprendizagens, alinhar planejamentos de ensino, e disputar sentidos para a educação nos espaços e tempos escolares:

"A implementação da BNCC está ocorrendo gradualmente ao longo do ano letivo, especialmente nas escolas estaduais, como exemplo, é possível citar o desenvolvimento de oficinas e instruções pedagógicas com o apoio do coordenador(a) da escola [...]. Os desafios são muitos especialmente relacionados ao corpo docente, pois algumas práticas ainda são bastante tradicionais, com métodos pouco inovadores. Como agravante, não temos suporte adequado na corrida para tal implementação. A resistência ao novo é grande, inovar é sempre difícil, sem o apoio e o auxílio adequado se torna ainda mais difícil. Os desafios da implementação da BNCC são percebidos especialmente pelo corpo docente, que precisam alinhar a sua prática pedagógica $e$ metodologias com os objetivos da BNCC" (PROFESSORA 1, Escola Estadual em Barreiras, Respostas ao Questionário, 11 de outubro, 2019). 


\begin{abstract}
"A implantação da BNCC é um fato! Porém, carece de formação e mais discussão nas escolas de Barreiras. O objetivo da BNCC é válido, pertinente, porém há muito que se investir em formação, recursos, estruturas físicas e pedagógicas de suporte para os profissionais envolvidos. [...] Relacionar habilidade / competência e operacionalização do objeto de conhecimento é um desafio. [...] A implementação vem repercutindo na minha prática de forma muito tímida, ainda. Muita açãolformação para acontecer" (PROFESSOR 2, Escola Estadual em Barreiras, Respostas ao Questionário, 13 de outubro, 2019).

"O processo de implementação está a passos lentos, isto é, precisa-se de mais reuniões, mais leituras, aprofundamentos... Tudo novo é sempre um desafio. E enfrentar o novo da um certo receio. A resistência que percebo é realmente encarar os desafios" (PROFESSOR 3, Escola Estadual em Barreiras, Respostas ao Questionário, 13 de outubro, 2019).
\end{abstract}

As políticas de tradução dos professores apresentam exaustivamente a dificuldade de compreensão da BNCC. A demanda por mais formação emerge, possivelmente, dessa dificuldade de integração e articulação política outra do currículo pela noção de competência. Embora a educação baseada em competências aí esteja desde muito antes dos Parâmetros Curriculares Nacionais, na década de 1990, que já a apresentava como possível tecnologia de organização curricular nas escolas, as críticas pelas quais essa perspectiva passou e vêm passando, sobretudo pelos seus rastros eficientistas ligados ao setor econômico, ao comportamentalismo, e ao discurso técnico-adaptacionista voltado à empregabilidade e a submissão da formação ao trabalho, tornaram-na menos expressiva na formação de professores nas últimas décadas (SILVA, 1999; PINAR, 2012; LOPES, 2008; LOPES; MACEDO, 2011; ANDERSON-LEVITT, 2017). Nas últimas décadas, parece ter ganhado muito mais destaque nas discussões sobre formação docente conceitos outros de integração de áreas disciplinares no currículo como, por exemplo, os estudos sobre interdisciplinaridade (FAZENDA, 1998; 2008; LOPES, 2008). Não vou adentrar aqui na discussão específica sobre políticas de formação docente e suas flutuações históricas, ligadas ou não à pedagogia das competências e à interdisciplinaridade. Com isso, quero apenas destacar que políticas que não levam em conta aspectos históricos e políticos da formação docente, levando em conta suas tradições disciplinares - não estou dizendo que sou a favor delas, destaco - tendem a promover dificuldades de adesão, compreensão e atuação nas escolas.

Em outros espaços, também discuti que essa demanda por mais formação para uma implementação mais direta, explícita, clara da BNCC nos relatos de professores, pode significar a dificuldade - e, ao mesmo tempo, o espaço mais aberto de significação - de traduzir a BNCC nos contextos. Ou seja, embora a BNCC busque produzir um padrão curricular, a tradução, enquanto processo marcado pela significação (re)criadora constituída pela diferença, faz emergir o momento da dificuldade de implementação. Acompanha essa dificuldade, a demanda por mais formação. Uma dificuldade que pode ser entendida como sendo parte do próprio processo de funcionamento de política padrão, na medida em que a ânsia por alinhamento dos fazeres curriculares produz não apenas a redução da docência a uma forma única de educar, como também a dificuldade dos professores em fazer essa forma 
única funcionar. Isso nos credencia pensar que, na própria governança instaurada pela política padrão, há uma desapropriação da docência criada pela necessidade do alinhamento visando a entrega encomendada. Trata-se de um processo que busca conter toda a diferença constitutiva dos processos tradutórios de políticas que são contexto-dependentes, na busca por produzir o efeito calculado da política na escolarização. Essa mesma dificuldade pode ser entendida como sendo parte da econômica dos sentidos produzidos na escola para o currículo, como uma aposta que o alinhamento e a padronização poderão produzir o efeito da competência esperado, disciplinando a diferença.

A partir das teorizações curriculares e de política pós-estruturais, é não só inviável e indesejável tentar produzir um efeito previamente definido na relação educativa com o outro (isto é, não deriva como efeito lógico da relação educativa um comportamento ou competência previamente definido), como também é considerado impossível conter a política em sua tradução nos espaços escolares (LOPES; MACEDO, 2011; PINAR, 2012; BIESTA, 2013; LACLAU; MOUFFE, 2015). Não há, portanto, forças de alinhamento e padronização capazes de uma planificação e economização absoluta dos sentidos escolares aptas a conter, de uma vez por todas, as dimensões envolvidas no complexo, não-linear, dinâmico e caótico processo da tradução e atuação da política nas escolas. E, talvez, não seja esse exercício saturante do poder o objetivo final da política padrão, mas, sim, o de continuar dizendo à escola e aos professores que, não importa os saberes que construíram ao longo de sua trajetória profissional, ele ainda é insuficiente. Isso porque o discurso da insuficiência, do fracasso, do atraso, do não alcance de resultados, entre outros, cria o próprio ambiente fragilizante de insegurança que viabiliza aquilo que se diz inovador e redentor da escola (TAUBMAN, 2009). O imaginário da economia dos sentidos produzido por política padrão nas escolas, com base nesses aspectos, tende tanto a gerar pressões e anseios por resultados muito específicos, como também a fracassar em seu desejo por disciplinamento da diferença, seja no nível da implementação da política, seja no nível do efeito que se espera produzir um comportamento derivado da maneira certa de implementar - com a política na ponta, isto é, na aprendizagem dos estudantes.

"A BNCC surgiu sem muita discussão, quase que uma imposição, sem tempo hábil para analisar e aplicar. Os êxitos acredito que sejam gradativos, ano após ano, pois, os próprios discentes sentem também o trabalho diferente e estão procurando se adaptar. A resistência seria à organização dos conteúdos. Ou seja, aquilo que é básico, prévio, aparece posteriormente. [...] A grande mudança nos currículos nos impossibilitou de conduzir o trabalho com tranquilidade (sem livro), recorrendo a autores diversos e tentando adaptar ao nível de entendimento do aluno e ao ano" (PROFESSORA 4, Escola Municipal em Barreiras, Respostas ao Questionário, 13 de outubro, 2019. Sem grifos no original).

"A implementação vem ocorrendo de uma forma que já foi estabelecida pela Secretaria Municipal de Educação com os objetos de conhecimento já prontos e que os professores devem seguir, e também com as habilidades. [...] Alguns professores tiveram alguma forma de resistência pelo fato de alguns conteúdos 
precisarem ser pesquisados sem recurso, pois não tem no livro didático. Com a implementação da BNCC na escola, houve uma grande melhoria, pois acho que os conteúdos são bastante interessantes e tem uma sequência mais lógica, os alunos de ciências começam a ver a parte de química e física das ciências naturais em todos os anos, não fica vendo somente no $9^{\circ}$ ano" (PROFESSORA 5, Escola Municipal em Barreiras, Respostas ao Questionário, 03 de outubro, 2019. Sem grifos no original).

A questão dos materiais de apoio à implementação materializa-se, quase que completamente, pela demanda do livro didático. A relação dos livros didáticos com a BNCC também emerge nos relatos dos professores. Aqui, as demandas e políticas tradutórias apontam para a ausência de conteúdos explícitos nos livros didáticos que estejam visivelmente adaptados às orientações da política. Acredito que há diversas nuances desse debate. Primeiro, um aspecto histórico mais relativo ao próprio fazer curricular na escola: a organização e o planejamento apresentados nos livros didáticos, em muitos contextos e, também, no Oeste da Bahia, parece continuar sendo a expressão mais encarnada do currículo escolar (FRACALANZA; MEGID-NETO, 2006). Ademais, os livros continuam sendo um material didático prioritariamente eleito, ao menos na perspectiva dos professores, tendo em vista aqueles que melhor adequam-se e dialogam com suas experiências de planejamento e organização curricular, com suas trajetórias profissionais, e com as orientações estaduais e municipais (FRACALANZA; MEGID-NETO, 2006). Trata-se de verdadeiros mapas, guias de orientação para o planejamento docente, que transitam, em seu uso, desde uma função mais referencial, de subsídio ao planejamento, até uma função mais instrumental e normativa nos currículos.

Assim, ao apresentar maneiras outras de organização do currículo pela via da integração por competências, em confronto com a tradicional forma de organização disciplinar, a política entra em confronto como os livros didáticos adotados até então pelos professores. $\mathrm{Na}$ perspectiva deles, isso faz com que o livro deixe de ser o material de apoio e de diálogo em sua tarefa de planejar. Desta forma, ressalto, mais uma vez, que políticas levadas à cabo pelo desprezo da experiência dos sujeitos envolvidos em sua atuação acabam por sucumbir às forças das traduções contextuais, envolvendo aí as formas de organização disciplinares, histórica e tradicionalmente, postas nos livros didáticos utilizados pelos professores, para mapear e orientar suas práticas. Não se trata aqui da defesa do uso do livro didático como único material didático de subsídio ao planejamento do currículo, tampouco da conservação dessa forma disciplinar nas escolas. Foco a atenção para o aspecto artificial e mecânico envolvido em desconsiderar tradições curriculares nas políticas de currículo, como se a norma, por si só, fosse capaz de criar as condições culturais, profissionais, formativas e políticas das múltiplas e imprevisíveis identidades forjadas para currículo que emergem das/nas relações escolares. A meu ver, esse conflito que emerge nos relatos com o livro didático pode também ser significado e compreendido desta forma, como uma querela entre políticas universalistas de regulação que "estreitam a gama de respostas criativas" (BALL; 
MAGUIRE; BRAUN, 2016, p. 14), e políticas da tradução nas escolas que realçam a capacidade de agência dos sujeitos ${ }^{10}$ ao lidar com elas.

O discurso da necessidade de transparência do planejamento do livro didático em relação à BNCC apresentado nos relatos dos professores pode ser teorizado e explorado, também, de outra forma. Por um lado, os professores avaliam que o livro didático não traz os conteúdos e a forma de trabalhá-los que possibilitem vinculá-los às habilidades. Aliás, essa é uma crítica que se estende a todo o processo formativo envolvendo a implementação da BNCC na região. Ainda assim, não se interroga, nesse sentido, a própria possibilidade de entrega encomendada do outro, a produção de versões autorizadas da alteridade (BHABHA, 2013) pela política e pelo ensino. Há, por outro lado, simultaneamente a avaliação da insuficiência do livro didático, uma crítica pelo fato de a BNCC querer ditar o currículo, isto é, apresentar uma listagem de objetos de conhecimento associados a habilidades e competências prévias. Ou seja, há tanto uma crítica ao livro didático porque ele não explicita a forma de vincular os conhecimentos ao desenvolvimento das competências esperadas, como há uma crítica à BNCC pelo fato dela normatizar o currículo. Podemos nos perguntar: afinal, se queremos certa liberdade para atuar em nosso exercício profissional, e criticamos a norma no sentido da sua perspectiva antidemocrática, não seria contraditório esperar ou desejar que algum material didático nos ensine a como colocá-la (a BNCC), exatamente, em prática? Parece haver, portanto, um paralelismo equivalente entre demandas supostamente contraditórias (algo previsto nas teorizações curriculares e de política aqui assumidas), sendo uma pela liberdade de atuação no currículo e, ao mesmo tempo, outra pela fantasia de estabilidade curricular fincada em anseios por algo que possa viabilizar a organização e dinâmica curricular da entrega de resultados.

Essa necessidade discursivamente construída da estabilidade do currículo para a entrega de resultados previamente delineados também faz parte do imaginário neoliberal na educação que Ball, Maguire e Braun (2016) caracterizam como deliverology. Como argumentei em outro momento, essa abertura discursiva mecânica e manufatureira da educação e do ensino, como se estivéssemos a produzir pessoas e perfis de sujeito com base em comportamentos e habilidades dadas e prévias, dentre outros motivos e razões, é o que vem viabilizando a hegemonização de discursos de padronização e planificação curricular numa dinâmica verticalizada de cascateamento de orientações e alinhamento, em múltiplos níveis de prática e fazer curricular. Isto é, a ideia de produzir orientações em um dado nível de discussão da política com a formulação de padrões e, em seguida, cascateá-los, de cima para baixo, visando alinhar as práticas às políticas. Tal imaginário da política curricular não só manifesta uma visão administrativa que separa política e prática, como se essa última não fosse, também, um espaço de produção de política, como aposta no sentido linear de uma tradução absoluta entre múltiplos níveis do fazer da política curricular, mantendo uma relação de cerceamento controle com a diferença e a disseminação de sentidos criados para o currículo.

"Nossa escola discutiu a BNCC durante a $1^{a}$ e a $2^{a}$ jornadas pedagógicas do ano de 2019. [...] As discussões não são aprofundadas, pois teríamos que ter um tempo mais longo de discussões. As Atividades Complementares que são 
realizadas por articuladores de área em um dia da semana, têm uma demanda de organização de projetos a serem realizados na escola de acordo com a programação da Secretaria de Educação da Bahia, ficando um tempo limitado para discussões da BNCC. Nesse sentido, nossas discussões, por enquanto, são incipientes. Existem professores que não estão dispostos à discussão, mesmo porque não acreditam que as propostas da BNCC possam se concretizar na íntegra como estão no documento. Pelo pouco que discutimos, estamos repensando nossa forma de conduzir o processo de ensino e aprendizagem para podermos criar um espaço mais condizente com as propostas da BNCC" (PROFESSORA 6, Escola Estadual em Barreiras, Respostas ao Questionário, 11 de outubro, 2019. Sem grifos no original).

Não apenas no contexto do Oeste da Bahia, mas nele também se faz presente, há posicionamentos de professores parcialmente contrários à norma curricular definida pela BNCC. A indisposição à discussão e à formação para a implementação da BNCC, pelo fato dos professores apresentarem certa discordância em relação à exequibilidade da política, faz surgir a questão: se a BNCC não é o currículo e não deve ser tomada como modelo obrigatório de configuração da prática escolar, qual é, então, o espaço para colocar políticas de currículo outras em curso, nas escolas, por aqueles/as que discordam de sua proposta? A linguagem do padrão curricular parece criar, também, a própria dificuldade de adesão por parte dos professores, na medida em que tenta forjar a ideia de que, satisfeitas as condições corretas da tradução da política, os efeitos esperados tornam-se explícitos na aprendizagem dos estudantes. Ou seja, na ausência da possibilidade de negociação com o contexto, a política expressa a ideia de que se as condições específicas da norma forem de tal forma bem traduzidas da política à prática, então a aprendizagem dos estudantes está garantida. A narrativa que condiciona a integralidade do sucesso da política à tarefa de bem traduzi-la pelos professores gera, também, a própria resistência dos mesmos, por avaliarem que, possivelmente, a integralidade da execução da norma pode ser impossível em seus contextos de prática. Os relatos críticos à exequibilidade integral da BNCC nos fazem pensar que não há, nem haverá, política curricular, qualquer que seja, capaz de forjar uma acomodação simples e direta entre seus princípios normativos e a pragmática contextual das práticas. Se a partir dos registros teóricos acima discutidos já é possível interpelar a ideia de uma tradução inequívoca da política, é da nodosidade contextual e das relações interpretativas com a norma que emergem políticas outras da diferença, tensionando os limites criados pelos padrões defendidos, disseminando sentidos e desconstruindo uma identidade sólida da política.

Apesar dos aspectos discordantes mencionados, arrisco afirmar que uma resistência clara, plenamente articulada e direta contra a política, é algo que, em minhas interpretações, não consegui captar no contexto investigado. Essas formas mais críticas de resistência, com a manutenção de contradiscursos a respeito da BNCC, parecem ser raras e pouco emergentes nas discussões no Oeste da Bahia. Na busca por atender as regulações da política, parece haver muito mais preocupação, tempo e espaço de discussão e formação nas escolas para pensar o como fazer da política, do que discussões e reflexões sobre a necessidade, propriamente dita, de uma base curricular, e da consequente restrição significante no fazer 
curricular que, dela, emerge. A partir dos referenciais aqui assumidos, arrisco dizer que parece ser parte dos jogos de poder e das narrativas geradas por políticas do tipo padrão, a criação dessa ambiência emergencial, aligeirada, restritiva, fazendo pensar que algo diferente da norma é impossível de ser executado em dado momento e contexto de prática. É nesse ponto que volto a exaltar a confiança e o potencial das teorias curriculares pós-estruturais e pós-fundacionais para pensar o currículo, justamente por encontrar nelas terreno fértil para oxigenar a cena curricular contemporânea, marcada por discursos de padronização, alinhamento, entrega de resultados, avaliações de performances de implementação, prestação de contas e pressões diversas sobre as escolas e os professores. Dessas teorizações, como venho defendendo em outros trabalhos, penso que qualquer decisão curricular é sempre uma decisão tomada em terreno indecidível, um terreno no qual há ausência de garantias absolutas quaisquer que sejam, e que qualquer norma estará, sempre, submetida às traduções contextuais. Esses aspectos centrais dessas teorias vêm permitindo interpelar, profundamente e de modo vigoroso, a metafísica da presença subjacente à ânsia por fazer uma política curricular tornar-se um universal absoluto, de fazê-la transparecer um sentido único, inequívoca e igualmente, a todos, de uma vez por todas, em todo e qualquer contexto.

\section{Considerações finais - traduções e sentidos em disputa e em fluxo}

Apesar de especificadas em suas particularidades, as políticas da tradução colocadas em curso no contexto do Oeste da Bahia conectam-se, em alguma medida, na ideia de que satisfeitas determinadas condições, é possível entregar aquilo que é encomendado, enquanto projeto de formação, pela BNCC. Ou seja, ponto comum em relação às políticas padrão em múltiplos contextos, a ânsia pela conduta do outro na formação por meio das competências funda uma metanarrativa escolar baseada na produção de resultados específicos. Ao mesmo tempo, tudo aquilo que essa narrativa implica se manifesta nas políticas da diferença e da tradução nos relatos docentes, sobretudo as pressões por: padronização, alinhamento de interpretações, controle e exatidão de implementação, contenção do diferir, objetificação do conhecimento, alcance de resultados de aprendizagem, avaliação e prestação de contas. Esses são alguns aspectos da política padrão e seu (des)fazimento no contexto investigado que quero destacar, realçando seus efeitos comuns a outros contextos, em múltiplas escalas de análise.

A meu ver, o desperdício das experiências e das trajetórias profissionais dos sujeitos colocado em curso pela BNCC cria uma dificuldade que não será resolvida pela substituição dos livros didáticos adaptados à BNCC, nem pela formação continuada para a organização do currículo pela integração por competências. Não se trata, defendo, de uma simples questão de mudança de livro didático e de oferta de formações que, em maior ou menor intensidade, acontecem de forma pouco eficaz nas escolas da região. Mudanças normativas profundas nas culturas profissionais como as impostas pela política padrão da BNCC, nesse sentido, tendem a sucumbir pelo fato de buscar ser um universal fechado às negociações, desprezando as trajetórias e singularidades dos sujeitos que, histórica e contextualmente, engendram os 
cotidianos escolares. Com o aprofundamento no registro pós-estrutural é possível, ainda, afirmar que mesmo um processo formativo prolongado no tempo, com mudanças estruturais e dos suportes necessários ao currículo, continuará sendo da ordem do impossível conter a diferença e as políticas da tradução operadas no chão da escola. Elas - as políticas - existem porque existe a interpretação singular de cada sujeito no encontro com o outro, seus interesses e dilemas, seus contextos de vida, trabalho e formação. Mesmo que o processo de implementação envolva uma série de atores que busquem conter as interpretações em falas autorizadas sobre a BNCC, em processos de formação continuada nas escolas, as políticas da diferença vazam, gotejam, corrompem e fazem emergir questões outras para além da norma.

Como venho argumentando e defendendo neste trabalho, a fase de implementação no contexto investigado vem fazendo emergir aspectos que vão desde as dificuldades de infraestrutura, de apoio pedagógico nas escolas, de interpretação da política, de gestão da formação continuada, de ausência de material didático, entre outros, até discordâncias parciais sobre a exequibilidade das políticas colocadas na BNCC. Compartilha com demais contextos o envolvimento de uma série de tecnologias de poder que buscam de-limitar a interpretação e o trabalho com a política nas escolas, visando o controle dos sentidos produzidos para alinhamento às normatizações propostas. A partir dos referenciais aqui trabalhados, por outro lado, defendo que a tradução de uma significação clara e unívoca para a BNCC, para todo e qualquer contexto curricular nacional, é uma operação impossível. Impossível não só pelo fato da incapacidade pan-óptica da política em exaurir todos os contextos, como já fica compreendido a partir de Ball e colaboradores (2016), mas pela impossibilidade mesma de exatidão da significação na tradução (DERRIDA, 2001).

Apesar de todos os esforços e demandas por mais formação, por mais material didático, por mais transparência e padronização, defendo que a prática da diferença continuará sempre conduzindo entendimentos e interpretações para um outro lugar, adiando, indefinidamente, o repouso da significação do currículo. Com isso, quero dizer que o que acontece em cada interpretação tradutória excede, e muito, o que poderia ser considerado um sentido estável para a BNCC, para o currículo escolar e para as práticas em sala de aula. Além disso, a significação produzida para o currículo e a formação está sempre submetida à destinerrância no diálogo com o outro com o qual buscamos estabelecer relações educativas. Isto é, há, também, tradução e negociação de sentidos com os estudantes sobre aquilo que julgamos ser o caminho mais adequado para fomentar a produção de conhecimento e as aprendizagens nas relações educativas. Tentar criar esforços contextuais e uma série de tecnologias econômicas de poder, no anseio de expulsar toda a diferença que habita essas operações, visando o alinhamento da docência e do currículo, só mostra que a BNCC é muito mais uma política preocupada em produzir uma visão única do que sejam boas práticas e bons currículos, bem ao tom do imaginário neoliberal (BALL, 2014; TAUBMAN, 2009), do que uma política preocupada em atenuar desigualdades e produzir equidade no ato de educar.

Não só no contexto do Oeste da Bahia, mas nele também se manifesta com certa intensidade, o que uma política de padrão curricular como a BNCC busca é deixar imóvel uma significação curricular, deixar frágil o professor e a docência, estancar a produção de sentidos na educação, na medida em que tenta padronizar projetos de vida e desautorizar a 
escola e os sujeitos que engendram seu cotidiano sobre a interpretação do próprio texto da política curricular, dizendo-lhes que há uma significação clara e transparente no texto a ser bem entendida e, inequivocamente, efetivada na prática escolar. Apesar desses esforços e tecnologias do poder, defendo que a vida escolar vai muito além de toda e qualquer política do tipo padrão, excedendo e infiltrando a normatividade, contorcendo-a por dentro, e manifestando a precariedade de toda e qualquer base interessada em instaurar o terrorismo do sentido único.

\section{Notas:}

1. Acompanho Lopes (2015), Macedo (2015), Hypólito (2019) e muitos outros na defesa de que ser contra bases curriculares nacionais não significa necessariamente ser contra a justiça social, equidade, inclusão, etc. Não só acreditamos ser impossível distribuir conhecimentos iguais para todos, porque não se trata de um objeto dado a ser entregue a outro, como também é desmedidamente injusto atribuir à escola o papel de corrigir injustiças socioeconômicas historicamente postas - talvez, esse discurso pragmático salvacionista seja a estratégia fragilizante propriamente dita das políticas de reformas educacionais, que diagnosticam o fracasso do objetivo impossível, visando responsabilização e controle da escola (PIMENTEL-JÚNIOR; CARVALHO, 2017).

2. Com isso, quero destacar que as articulações políticas envolvidas nas distintas etapas - produção e instituição da BNCC e, agora, mais recentemente, a implementação nas escolas - de trabalho com a Base fazem emergir redes de solidariedade complexas. Essas redes envolvem demandas e zonas de equivalência entre agentes públicos, privados, de direita, de centro, de esquerda, conservadores, progressistas, entre outros, sem uma essência setorial ou centro único de interesse a comandar este processo.

3. Entendendo, por decisão, um ato de poder marcado pela inclusão e exclusão de caminhos possíveis, sem um fundamento determinístico último e/ou uma necessidade inexoravelmente sistêmica como o texto e os discursos vinculados à BNCC fazem parecer.

4. Resolvi não desenvolver uma extensa explicitação teórica sobre os referenciais do trabalho de modo a privilegiar os resultados da pesquisa no texto.

5. Em seus estudos, Ball e outros colaboradores vêm defendendo a metáfora da caixa de ferramentas como uma forma de empreender uma abordagem multi-política, visando traçar e compreender, de modo mais holístico-realista, as atuações de políticas nas escolas. Defende que contar histórias sobre as formas rotineiras e complexas pelas quais políticas são colocadas em ação nas escolas envolve sempre uma mobilização de recursos teóricos combinados, tentando entrelaçar as facetas que consideram constituintes do trabalho com políticas.

6. Os relatos que formam o material empírico da pesquisa foram construídos mediante questionários disponibilizados aos professores e professoras das escolas da rede municipal e estadual de Barreiras, Bahia, em encontros de Atividade Complementar promovidos para discussão e formação da/na BNCC.

7. Assim como Ball, Maguire e Braun (2016) penso que rastrear a realização das especificidades da política em sala de aula exigiria uma análise de trajetória não apenas complexa, por tentar conectar os eventos da sala de aula à interpretação da política, como também pouco informativa em termos heurísticos para os propósitos da pesquisa. Buscar essa trajetória significaria apostar em uma etnografia reflexiva da sala de aula que não foi objetivo da pesquisa. Também não foi objeto da investigação perseguir os efeitos da política em termos de ensino aprendizagem e, aliás, esse é um dos aspectos problematizados em nossas discussões.

8. A partir das teorias assumidas, ficam claras as limitações do trabalho para falar em nome de uma unidade sociológica significada como Oeste da Bahia. A limitação deste trabalho não se dá apenas pela impossibilidade de cobrir, empiricamente, os relatos do contexto, mas pela ausência mesma de fixidez das 
significações e dos discursos investigados. Não se trata de uma unidade uníssona em seus posicionamentos, tampouco configurada por uma mesmidade de sentidos sobre a BNCC. Apesar disso, entendo que se trata de ponderações possíveis tendo em vista os relatos docentes com os quais tive contato, e que formam o material empírico da pesquisa.

9. Uma distinção disponível não apenas no documento, mas também em: http://basenacionalcomum.mec.gov.br/a-base. Acesso em 17/08/2020.

10. Não falo aqui de uma agência fundacionista dos sujeitos como se fossem portadores da consciência absoluta das transformações pelas que as políticas, os livros didáticos e as escolas precisam passar para serem mais adequadas aos seus contextos e fazeres curriculares - também eles (contextos e currículos), são construtos discursivos em constante disputa. Refiro-me a uma agência muito mais marcada pelo que Certeau (2009) fala acerca do uso em sua obra voltada às práticas cotidianas, uma agência fraca que opera por dentro e sobre os escombros discursivos hegemônicos, silenciosa, quiçá tradutória, nos sentidos de tradução aqui trabalhados.

\section{Referências}

SOBRENOME DO AUTOR, Prenomes do autor por extenso e intermediários abreviados. Título: subtítulo. Edição. Local de publicação: Editora, ano.

ANDERSON-LEVITT, K. Global Flows of Competence-based Approaches in Primary and Secondary Education. Cahiers de la recherche sur l'éducation et les savoirs, n. 16, p. 47-72, 2017. Disponível em: < $\quad$ https://deepblue.lib.umich.edu/bitstream/handle/2027.42/151927/CRES16_3\%20AndersonLevitt.pdf?sequence $=1 \&$ isAllowed=y $>$ Acesso em: 10 de ago. 2020

BALL, S. J. Educational reform: a critical and post-structural approach. Buckingham, Philadelphia: Open University Press, 1994.

BALL, S. J. Diretrizes Políticas Globais e Relações Políticas Locais em Educação. Currículo sem Fronteiras, v. 1, n. 2, p.99-116, 2001.

BALL, S. J. Educação Global S. A.: novas redes políticas e o imaginário neoliberal. Ponta Grossa: Editora UEPG, 2014.

BAll, S. J.; MAguire, M.; BRAUN, A. Como as Escolas Fazem as Políticas: atuação em escolas secundárias. Ponta Grossa: Editora UEPG, 2016.

BENNINGTON, G; DERRIDA, J. Jacques Derrida. Rio de Janeiro: Jorge Zahar Editor, 1996.

BHABHA, H. K. O local da cultura. Belo Horizonte: Ed. UFMG, 2013.

BIESTA, G. Para Além da Aprendizagem: educação democrática para um futuro humano. Belo Horizonte: Autêntica, 2013.

BIESTA, G. The Beautiful Risk of Education. London: Routledge, 2016.

BRASIL. Ministério da Educação. Base Nacional Comum Curricular: educação é a base. Ensino Médio. Brasília, DF: MEC, 2018.

BUTLER, J. Quadros de Guerra: quando a vida é passível de luto? Rio de Janeiro: Civilização Brasileira, 2017.

CERTEAU, M. A Invenção do Cotidiano: 1. Artes de fazer. 16ed. Petrópolis: Vozes, 2009.

DERRIDA, J. Margens da Filosofia. Campinas: Papirus, 1991.

DERRIDA, J. Posições. Belo Horizonte: Autêntica, 2001.

DERRIDA, J. Papel-Máquina. São Paulo: Estação Liberdade, 2004. 
DERRIDA, J. Observações sobre Desconstrução e Pragmatismo. In: MOUFFE, C. (Org.). Desconstrução e Pragmatismo. Rio de Janeiro: Mauad X, 2016.

LOPES, A. Políticas de Integração Curricular. Rio de Janeiro: EdUERJ, 2008.

LOPES, A. C.; CUNHA, E.; COSTA, H. H. C. Da recontextualização à tradução: investigando políticas de currículo. Currículo sem Fronteiras, v. 13, n. 3, p. 392-410, 2013.

LOPES, A. C.; MACEDO, E. Teorias de Currículo. São Paulo: Cortez, 2011.

MACEDO, E. Mas a Escola não tem que Ensinar? Conhecimento, reconhecimento e alteridade na teoria do currículo. Currículo Sem Fronteiras, v. 17, n. 3, p. 539-554, 2017.

MACEDO, E. Fazendo a Base virar realidade: competências e o germe da comparação. Retratos da Escola, v. 13, n. 25, p. 39-58, 2019. DOI: https://doi.org/10.22420/rde.v13i25.967

FAZENDA, I. (org.). Didática e Interdisciplinaridade. Campinas: Papirus, 1998.

FAZENDA, I. O que é Interdisciplinaridade? São Paulo: Cortez, 2008.

FRACALANZA, H.; MEGID-NETO, J. (Orgs.). O livro Didático de Ciências no Brasil. Campinas: Editora Komedi, 2006.

FRANGELLA, R. C. P. Padrão-Política: fincando prioridade e propriedade no terreno educacional. Currículo sem Fronteiras, v. 19, n. 3, p. 828-843, 2019. DOI: http://dx.doi.org/10.35786/1645-1384.v19.n3.02

HYPOLITO, A. M. BNCC, Agenda Global e Formação Docente. Retratos da Escola, v. 13, n. 25, p. 187-201, 2019. DOI: http://dx.doi.org/10.22420/rde.v13i25.995

OTTONI, P. Tradução: a prática da diferença. Campinas: Editora da Unicamp, 2005.

PIMENTEL-JÚNIOR, C.; CARVALHO, M. I. S. S. Profanando o papel da escola? Narrativas pós-modernas sobre o processo social de escolarização. Práxis Educacional, v. 13, p. 161-183, 2017. DOI: http://dx.doi.org/10.22481/praxis.v13i24.935

PIMENTEL-JÚNIOR, C.; CARVALHO, M. I. S. S.; SÁ, M. R. G. B. Currículo, (Auto)biografias e Diferença: políticas e poéticas do incontrolável no cotidiano da educação em ciências. Revista E-Curriculum, v. 16, n. 1, p. 29-59, 2018. DOI: http://dx.doi.org/10.23925/1809-3876.2018v16i1p29-59

PIMENTEL-JÚNIOR, C. Demandas Identitárias nas Políticas de Currículo para o Ensino das Ciências. Revista Atos de Pesquisa em Educação, v. 15, n. 1, p. 94-119, 2020. DOI: https://dx.doi.org/10.7867/18090354.2020v15n1p94-119

PIMENTEL JÚNIOR, C. Demandas discursivas regulatórias para "fazer a BNCC sair do papel" no Oeste da Bahia. Roteiro, v. 46, p. e23806, 2020. DOI: https://doi.org/10.18593/r.v46i0.23806

PINAR, W. A equivocada educação do público nos Estados Unidos. In: GARCIA, R. L.; MOREIRA, A. F. B. (Orgs.). Currículo na Contemporaneidade: incertezas e desafios. 4ª ed. São Paulo: Cortez, 2012.

SILVA, T. T. Documentos de Identidade: uma introdução às teorias do currículo. Belo Horizonte: Autêntica, 1999.

SISCAR, M. Jacques Derrida: literatura, política, tradução. Campinas: Autores Associados, 2012.

TAUBMAN, P. Teaching by Numbers: deconstructing the discourse of standards and accountability in Education. New York, Routledge, 2009. Disponível em: <https://www.researchgate.net/file.PostFileLoader.html?id=567ae7f7614325f5548b457c\&assetKey=AS\% 3A309891711864833\%401450895349621> Acesso em: 10 ago. 2020.

WOLFREYS, J. Compreender Derrida. Petrópolis, Rio de Janeiro: Vozes, 2009. 


\section{Correspondência}

Clívio Pimentel Júnior: Doutor em Educação pelo Programa de Pós-Graduação em Educação, Universidade Federal da Bahia. Professor no Programa de Pós-Graduação em Ensino, no Centro das Humanidades, da Universidade Federal do Oeste da Bahia. Líder do Grupo de Pesquisa Políticas de Currículo, Diferença, Educação em Ciências. Sócio da Associação Brasileira de Currículo (ABdC) e da Associação Nacional de Pós-graduação e Pesquisa em Educação (ANPED). Tem se dedicado ao estudo na área de Educação - (Auto)Biografias e Formação de Professores; Currículo, Cultura e Cotidiano escolar; Política de Currículo, Diferença e Ensino de Ciências e Biologia.

E-mail: cpjunior@ufob.edu.br

Texto publicado em Currículo sem Fronteiras com autorização dos autores. 